\title{
O empregio da biomicroscopia ultra-sônica no diag̉nósticoe evolução clínica dos diferentes tipos de esclerite anterior
}

\author{
Application of ultrasound biomicroscopy in the diagnosis and clinical evolution of \\ different typesof anterior scleritis
}

Telma Sternlicht ${ }^{1}$

Norma Allemann²

Cristina Muccioli ${ }^{3}$

\section{RESUMO}

Objetivo: Correlacionar achados da biomicroscopia ultra-sônica(UBM)com tipos de esclerite anterior. Métodos: Foram avaliados seis pacientes encaminhados ao Setor de Ultra-som do Departamento de Oftalmologia da Universidade Federal de São Paulo - Escola Paulista de Medicina, com suspeita clínica de esclerite anterior, utilizando-se o ultra-som de alta freqüência (transdutor de $50 \mathrm{MHz}$ ) para elucidação das alterações histopatológicas encontradas na esclerite anterior. Resultados: Pacientes com esclerite nodular apresentaram lesão escleral bem delimitada, homogênea, hiporrefletiva, com espessamento localizado e hiporrefletividade dos tecidos adjacentes. Pacientes com esclerite difusa apresentaram espessamento escleral heterogêneo, de aspecto "moteado". Pacientes com esclerite necrotizante apresentaram perda de tecido com afinamento escleral e alterações vítreas adjacentes. Conclusão: A biomicroscopia ultra-sônica é excelente método não-invasivo para se diferenciar os tecidos oculares acometidos durante o processo de esclerite anterior, auxiliando o profissional no diagnóstico e, conseqüentemente, no tratamento das lesões.

Descritores: Esclerite/ultra-sonografia; Esclerite/diagnóstico; Ultra-sonografia/métodos; Microscopia/métodos

\section{INTRODUÇÃO}

A esclerite anterior [muitas vezes constituindo sinal clínico de vasculite sistêmica ${ }^{(1)}$, é classificada, segundo Watson e Hayreh ${ }^{(2)}$, em nodular, difusa e necrozante, de acordo com características clínicas e anatômicas.

A classificação anatômica inicia-se pelo exame biomicroscópico feito à lâmpada de fenda e ectoscopia com o uso de iluminação natural ou auxílio de lanterna. Muitas vezes, não é possível identificar os limites da inflamação escleral, bem como os tecidos oculares propriamente envolvidos.

Com o desenvolvimento dos transdutores ultra-sônicos de alta freqüência utilizados na biomicroscopia ultra-sônica, o tecido escleral é identificado de acordo com suas características acústicas internas ${ }^{(3)}$, permitindo assim a distinção entre áreas de inflamação e áreas de necrose.

Este estudo tem como objetivo avaliar a importância da biomicroscopia ultra-sônica no auxílio diagnóstico e classificação anátomo-patológica dos tipos de esclerite anterior, como método não invasivo de rápida execução.

\section{MÉTODOS}

Foram avaliados seis pacientes encaminhados ao Setor de Ultra-som do Departamento de Oftalmologia da Universidade Federal de São Paulo - 
Escola Paulista de Medicina, com diagnóstico clínico de esclerite anterior, baseado em sintomas e sinais observados ao exame biomicroscópico inicial. Quatro pacientes eram do sexo feminino, com idade média de 50,5 anos (43-58 anos) e dois do sexo masculino, com idades de 23 e 74 anos.

Estes pacientes foram submetidos ao exame de biomicroscopia ultra-sônica (UBM), utilizando-se aparelho Ultrasound Biomicroscope modelo 840 (Humphrey Instruments, EUA) equipado com um transdutor de $50 \mathrm{MHz}$ de freqüência. Após a instilação de uma gota de colírio Anestésico ${ }^{\circledR}$ - Allergan-Frumtost (cloridrato de tetracaína e de cloridrato de fenilefrina associado ao ácido bórico) no olho a ser examinado, colocouse uma cuba plástica rígida entre as pálpebras do paciente, preenchendo-a com substância visco-elástica (colírio de metilcelulose a $2 \%{ }^{\circledR}$, Ophthalmos, São Paulo), a qual se manteve em contato direto com o olho. Prosseguiu-se a técnica de imersão ${ }^{(4)}$ para o exame do local, sempre acompanhado com o registro de fotografias das áreas acometidas, emitindo-se finalmente relatórios descritivos e por vezes com medida da extensão do comprometimento.

\section{RESULTADOS}

Dos seis pacientes examinados, três apresentaram, segundo padrões ultra-sonográficos, esclerite nodular; um destes pacientes retornou ao serviço em outras ocasiões com recidivas da doença ocular e afinamento escleral sequelar; outro paciente apresentava conjuntamente uma área de esclerite difusa (Tabela 1).

Três pacientes apresentaram esclerite necrozante em atividade.

Quanto aos pacientes com esclerite nodular, observou-se pela UBM áreas bem delimitadas, homogêneas e hiporrefletivas de esclera, com discreta insinuação para a superfície anterior (provável infiltração inflamatória associada ao edema dos tecidos adjacentes). Todos os pacientes apresentaram hiporrefletividade e espessamento do corpo ciliar subjacente e da episclera suprajacente (Figura 1).

O padrão ultra-sonográfico observado no paciente com esclerite difusa foi de heterogenicidade (aspecto "moteado") e espessamento escleral, contrastando com a aparência uniforme e hiperrefletiva da esclera adjacente; o processo inflamatório comprometia também o corpo ciliar subjacente e a episclera suprajacente, com diminuição da refletividade interna e espessamento local (Figura 2).

Os três pacientes com esclerite necrozante apresentaram ao exame áreas de hiporrefletividade caracterizadas por perda de tecido e afinamento escleral; encontrou-se em dois deles ecos sugestivos de membranas na base vítrea (Figura 3), enquanto que um dos pacientes ainda apresentou eco membranáceo de alta refletividade fixo e periférico, sugestivo de descolamento de coróide localizado e reação celular inflamatória de câmara anterior caracterizada por ecos puntiformes móveis e hiporrefletivos.

\section{DISCUSSÃO E CONCLUSÃO}

A ultra-sonografia clínica tem se mostrado de grande valia na detecção, diferenciação e mensuração de tecidos ou alterações oculares. Entretanto, a resolução do aparelho fica limitada de acordo com a freqüência utilizada ${ }^{(5-6)}$. O desenvolvimento de transdutores de alta freqüência $(50$ a $100 \mathrm{MHz})$ acoplados ao dispositivo do modo-B oferecem a possibilidade de maior resolução axial e lateral, embora com menor pene-

\begin{tabular}{|c|c|c|c|}
\hline $\begin{array}{l}\text { Sexo, idade (anos), } \\
\text { olho acometido }\end{array}$ & Tipo de esclerite & Achados clínicos & Achados na UBM \\
\hline$M, 23, O D$ & Nodular & $\begin{array}{l}\text { Nódulo escleral nasal bem } \\
\text { delimitada, hiperemiado }\end{array}$ & $\begin{array}{l}\text { Área de hiporrefletividade e homogeneidade escleral bem } \\
\text { delimitada, com hiporrefletividade e espessamento do corpo } \\
\text { ciliar e episclera adjacentes }\end{array}$ \\
\hline$F, 45, \mathrm{OE}$ & Nodular e difusa & $\begin{array}{l}\text { Nódulo escleral nasal infe- } \\
\text { rior e hiperemia difusa nasal } \\
\text { superior }\end{array}$ & $\begin{array}{l}\text { Lesão bem delimitada de hiporrefletividade interna nasal } \\
\text { inferior e espessamento com heterogeneidade nterna nasal } \\
\text { superior, com espessamento e hiporrefletividade de } \\
\text { conjuntiva e episclera adjacentes }\end{array}$ \\
\hline $\mathrm{M}, 75, \mathrm{OE}$ & $\begin{array}{l}\text { Nodular e afinamento } \\
\text { escleral sequelar }\end{array}$ & $\begin{array}{l}\text { Nódulo escleral superior e } \\
\text { afinamento escleral nasal } \\
\text { superior }\end{array}$ & $\begin{array}{l}\text { Lesão bem delimitada com hiporrefletividade interna e } \\
\text { homogeneidade superior e afinamento escleral nasal superior }\end{array}$ \\
\hline$F, 58, O D$ & Necrozante & $\begin{array}{l}\text { Afinamento escleral tempo- } \\
\text { ral superior }\end{array}$ & $\begin{array}{l}\text { Afinamento escleral, membranas na base vítrea adjacente } \\
\text { e edema conjuntival }\end{array}$ \\
\hline$F, 43, \mathrm{OE}$ & Necrozante & $\begin{array}{l}\text { Afinamento escleral temporal } \\
\text { inferior peri-límbico, reação } \\
\text { celular na câmara anterior }\end{array}$ & $\begin{array}{l}\text { Afinamento escleral, ecos puntiformes na câmara anterior, } \\
\text { ecos membranáceos de média refletividade na base } \\
\text { refletividade sugestivo de descolamento de coróide }\end{array}$ \\
\hline$F, 53, \mathrm{OE}$ & Necrozante & $\begin{array}{l}\text { Afinamento escleral nasal } \\
\text { superior }\end{array}$ & Afinamento escleral \\
\hline
\end{tabular}




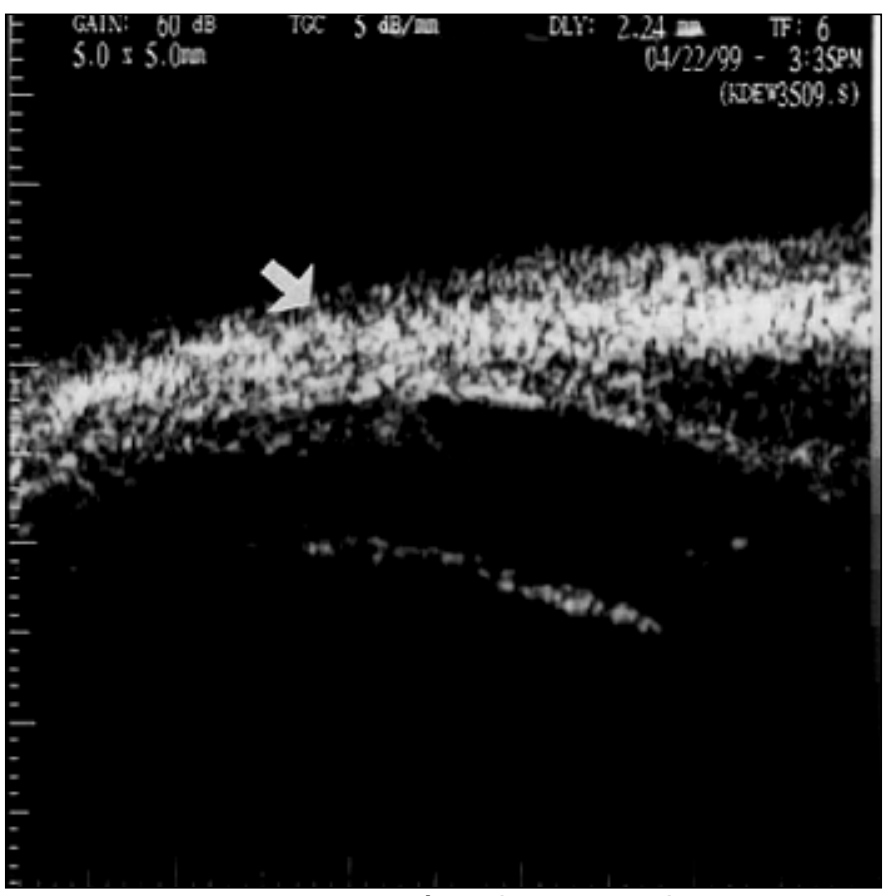

Figura 1 - Biomicroscopia ultra-sônica (UBM, $50 \mathrm{MHz}$ ) de um olho com esclerite nodular. Notar a área de hiporrefletividade e espessamento localizados da esclera (seta)

tração no tecido (aproximadamente $4 \mathrm{~mm}$ de profundidade axial, com resolução lateral de 20 micrômetros). Esta resolução excede cerca de quatro a seis vezes a obtida com o ultra-som convencional de $10 \mathrm{MHz}^{(3,5)}$. A penetração relativamente pequena é suficiente para estudar as estruturas do segmento anterior como a esclera, objeto do estudo em questão, permitindo análises apuradas e evitando-se a utilização de procedimentos mais invasivos ${ }^{(7-8)}$.

A esclera constitui uma camada de baixa distensibilidade, com espessura que varia de $0,3 \mathrm{~mm}$ (a nível das inserções dos músculos retos) a 1,0 mm (próximo ao nervo óptico), composta por feixes densos de colágeno, poucas fibras elásticas, poucos fibroblastos e quantidade moderada de proteoglicanos e glicoproteínas ${ }^{(9)}$.

Em condições normais, a esclera é altamente refletiva em comparação à córnea, o que permite a delimitação da junção córneo-escleral pelo exame de $\mathrm{UBM}^{(6)}$. Esta diferença de refletividade pode ser explicada pela disposição irregular dos feixes de colágeno no tecido escleral. As superfícies anterior e posterior da esclera são delimitadas pela diferença de refletividade interna, já que a episclera suprajacente e o corpo ciliar subjacente são menos refletivos.

$\mathrm{Na}$ esclerite, a baixa refletividade escleral evidenciada à UBM é explicada histologicamente pelo edema e pela desorganização das lamelas colágenas devido a aglomerados de células inflamatórias ${ }^{(1,10)}$.

Os achados encontrados nesse estudo condizem com as alterações relatadas por outros autores ${ }^{(6,11)}$ : as esclerites nodulares se apresentaram como áreas de hiporrefletividade in-



Figura 2 - Biomicroscopia ultra-sônica (UBM, $50 \mathrm{MHz}$ ) de um olho com esclerite difusa demonstrando o padrão heterogêneo de refletividade e de espessamento escleral, sem localização definida (padrão "moteado"). Notar que o processo inflamatório acomete também o corpo ciliar subjacente e a episclera suprajacente (seta)

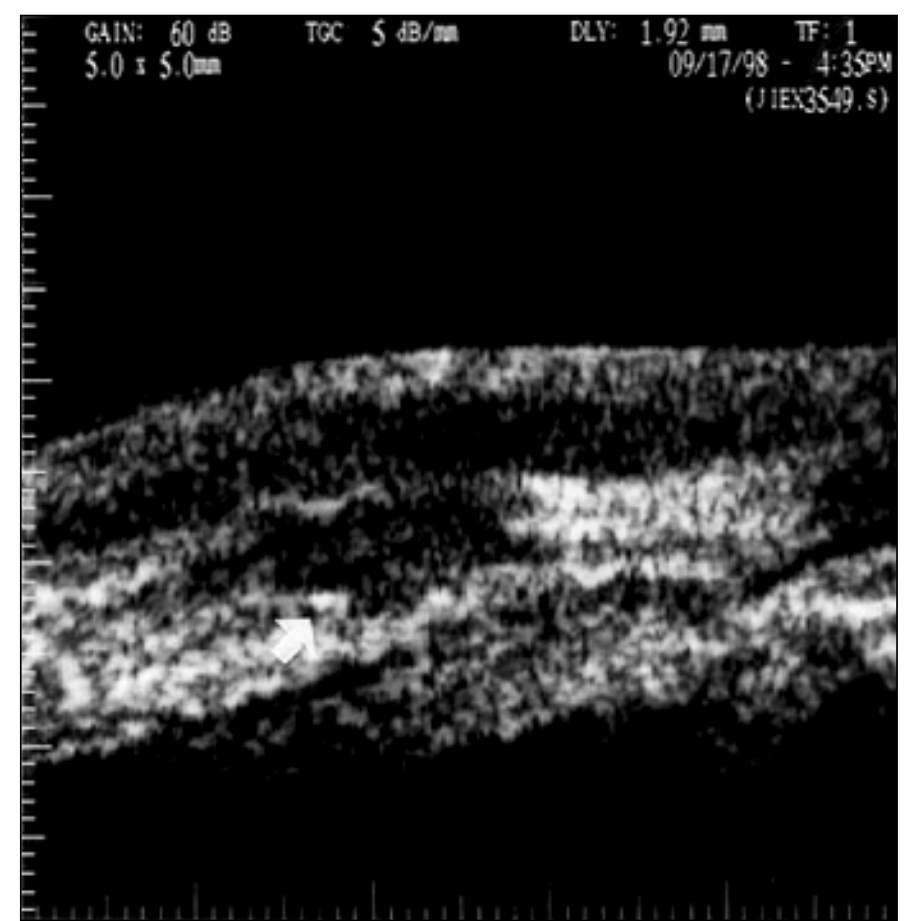

Figura 3 - Biomicroscopia ultra-sônica (UBM, $50 \mathrm{MHz}$ ) de um olho com esclerite necrozante com evidente afinamento escleral (seta) e membranas na base vítrea

terna, com espessamento escleral focal de bordas distintas, havendo na maioria dos casos espessamento episcleral e ciliar 
conjuntos. Observou-se neste estudo em um paciente com esclerite nodular, áreas de afinamento escleral secundário a nódulos antigos, semelhante ao estudo de Pavlin e cols. ${ }^{(6)}$, o que não foi observado por Heiligenhaus e cols. ${ }^{(11)}$.

As alterações estruturais encontradas na esclerite difusa, revelando aspecto "moteado" (alternância entre áreas de maior e menor refletividade) e espessamento escleral heterogêneo também foram relatadas por outros autores ${ }^{(6,11)}$. Esclerites nodulares ou difusas podem evoluir para necrose ${ }^{(1)}$; a inflamação torna-se granulomatosa, com degeneração do colágeno e necrose celular, levando ao afinamento escleral, o qual é facilmente mensurado pela $\mathrm{UBM}^{(6,11-12)}$. Se o afinamento é evidente, a UBM pode indicar a necessidade de enxertos esclerais $^{(6,13)}$ e até prever a extensão e a posição apropriada para os mesmos.

A esclerite necrozante pode cursar com alterações reacionais vítreas, resultando em afinamento escleral, como observado em dois casos neste estudo e por Pavlin e cols. ${ }^{(6)}$.

Embora não correlacionado neste estudo, o grau de atividade inflamatória visto ao exame biomicroscópico de lâmpada de fenda pode não corresponder aos achados da $\mathrm{UBM}^{(11)}$; assim, uma esclerite classificada clinicamente como nodular pode já apresentar alterações necróticas somente observadas ao exame ultra-sonográfico. Daí, a importância em se submeter o paciente com esclerite a tal método diagnóstico, somando os resultados aos aspectos clínicos para obtenção do tratamento específico adequado.

Como conclusão final, a biomicroscopia ultra-sônica tem sido de grande utilidade na distinção dos tecidos oculares comprometidos durante a evolução clínica das esclerites anteriores.

\section{ABSTRACT}

Purpose: To correlate findings on ultrasound biomicroscopy with types of anterior scleritis. Methods: Six patients with clinical findings of anterior scleritis were examined by ultrasound biomicroscopy ( $50 \mathrm{MHz}$ transducer), performed at the Ocular Ultrasound Section of Universidade Federal de São
Paulo - Escola Paulista de Medicina for elucidation of histopathological alterations in anterior scleritis. Results: Patients with nodular scleritis had well-limited lesions, with homogeneously low reflectivity and localized increased thickness with lower reflectivity of adjacent tissues. Patients with diffuse scleritis had an heterogeneous increased thickness with heterogeneous reflectivity (a mottled appearance). Patients with necrotizing scleritis presented loss of tissue with scleral thinning and inflammatory adjacent vitreous changes. Conclusions: Ultrasound biomicroscopy is an excellent noninvasive method in identifying involved ocular tissues in anterior scleritis, helping the ophthalmologist in his/her diagnosis and treatment.

Keywords: Scleritis/ultrasonography; Scleritis/diagnosis; Ultrasonography/methods; Microscopy/methods

\section{REFERÊNCIAS}

1. Foster CS, Sainz de la Maza M. Clinical considerations of episcleritis and scleritis: the Massachussets eye and ear Infirmary experience. In: Foster CF, de la Maza MS. The sclera. New York: Springer-Verlag; 1994. p. 95-136.

2. Watson PG, Hayreh SS. Scleritis and episcleritis. Br J Ophthalmol 1976;60: 163-91.

3. Pavlin CJ, Harasiewicz K, Sherar MD, Foster FS. Clinical use of ultrasound biomicroscopy. Ophthalmology 1991;98:287-95.

4. Pavlin CJ. Practical application of ultrasound biomicroscopy. Can J Ophthalmol 1995;30:225-9.

5. Pavlin CJ, Sherar MD, Foster FS. Subsurface ultrasound microscopic imaging of the intact eye. Ophthalmology 1990;97:244-50.

6. Pavlin CJ, Easterbrook M, Hurwitz JJ, Harasiewicz K, Eng P, Foster FS Ultrasound biomicroscopy in the assessment of anterior scleral disease. Am J Ophthalmol 1993;116:628-35.

7. Ossoinig KC. Standardized echography: basic principles, clinical applications, and results. Int Ophthalmol Clin 1979;19:127-210.

8. Allemann N. Biomicroscopia ultra-sônica. Arq Bras Oftalmol 1995;58:283-5

9. Foster CS, Sainz de la Maza M. Structural considerations of the sclera. In: Foster CS, de la Maza MS. The sclera.New York; Springer-Verlag; 1994. p. 1-32.

10. Bernauer W, Watson PG, Daicker B, Lightman S. Cells perpetuating the inflammatory response in scleritis. Br J Ophthalmol 1994;78:381-5.

11. Heiligenhaus A, Schilling M, Lung E, Steuhl KP. Ultrasound biomicroscopy in scleritis. Ophthalmology 1998;105:527-34.

12. Meller D, BoKer T. Complications of misdiagnosed and inadequately treated necrotizing scleritis studied by ultrasound biomicroscopy and computerized corneal topography. Int Ophthalmol 1997;21:35-7.

13. Sainz de la Maza M, Tauber J, Foster CS. Scleral grafting for necrotizing scleritis. Ophthalmology 1989;96:306-10.

\title{
Novidades na Internet!!!
}

\author{
Agora no site CBO você tem disponível todas as informações na íntegra dos \\ Arquivos Brasileiros de Oftalmologia \\ http://wWw.cbo.com.br/abo
}

